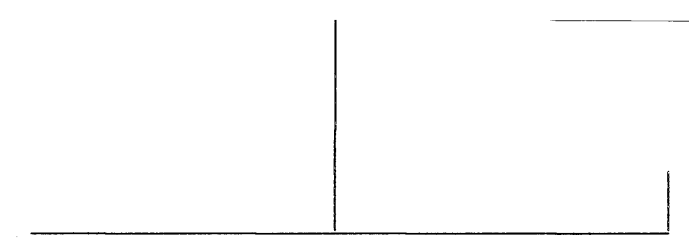

Rev. Latinoam. Psicopat. Fund., IX, 3, 433-446

\title{
Psicopatologia da autonomia: a importância do conhecimento psicopatológico nos novos dispositivos de assistência psiquiátrica*
}

\author{
Erotildes Maria Leal \\ Octávio Domont de Serpa Júnior \\ Nuria Malajovich Muñoz \\ Nelson Goldenstein \\ Pedro Gabriel G. Delgado
}

\begin{abstract}
O lugar que o conhecimento psicopatológico tem ocupado, e pode vir a ocupar na prática clínica dos centros de atenção psicossocial (CAPS) - serviços comunitários destinados ao tratamento de pacientes com transtornos mentais graves, persistentes, em quadros agudos ou não - é a questão central deste artigo. Analisam-se brevemente as conseqüências da hegemonia da psicopatologia descritiva para o desenho das intervenções nesses serviços e discutese se a psicopatologia do ser social poderia ser ferramenta para o construção de cuidado que visa promover a autonomia possível para os pacientes viverem em comunidade.
\end{abstract}

Palavras-chave: Autonomia, psicopatologia do ser social, psicopatologia do senso comum, atenção psicossocial

* Trabalho apresentado no XXIII Congresso Brasileiro de Psiquiatria, Belo Horizonte, 2005. Mesa: Desafios Contemporâneos da Psicopatologia. 


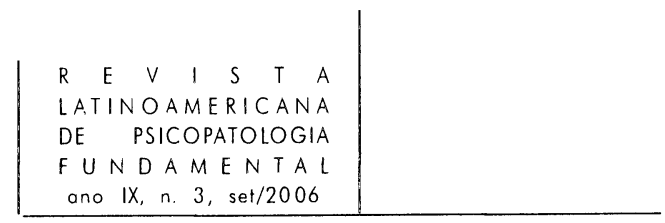

\section{Introdução}

A discussão apresentada aqui é fruto de reflexão que vem sendo produzida no Laboratório de Estudos e Pesquisas em Psicopatologia e Subjetividade do Instituto de Psiquiatria da UFRJ. Está em desenvolvimento uma linha de investigação sobre o lugar que o conhecimento psicopatológico tem ocupado, e pode vir a ocupar, na prática clínica exercida nos novos dispositivos da assistência psiquiátrica brasileira. O propósito é nos auxiliar a saber melhor sobre o cuidado que temos produzido nesses serviços.

O desenho do cuidado na rede de atenção territorial organiza-se sobre um paradigma que contempla a possibilidade de pacientes psiquiátricos graves e em crise serem tratados na comunidade e ali viverem com o grau de autonomia que lhes for possível. O desafio central desses serviços é a criação de uma atenção que tenha como eixo a questão da inserção social, pondo a operar:

a) diferentes modos de conceber a loucura;

b) diferentes tratamentos;

c) variáveis existentes no espaço social que interferem diretamente na evolução dos transtornos mentais.

O cuidado, para garantir tais características, não pode tomar o homem como uma mônada, não pode considerar a subjetividade humana exclusivamente a partir do corpo biológico ou da interioridade psicológica, variações do modo reducionista e ainda hegemônico de descrevê-la na contemporaneidade. Tomar a subjetividade como expressão da relação humano-social é condição para o tipo de cuidado que se desenha sob essa perspectiva. Como este será sempre organizado em torno de valores e escolhas, devemos nos esforçar para não transformar esses mesmos valores e escolhas em normas inflexíveis, atemporais, eternas, a-históricas e frequientemente excludentes, porque exigem dos pacientes uma adequação incondicional a elas.

Os vetores que concorrem para o cuidado seguir quer o caminho da normalização - imposta do exterior - quer o da normatividade possível a cada indivíduo em sofrimento são inúmeros e complexos. Estão no âmbito dos saberes e das práticas científicas e laicas que hoje constituem o campo do cuidado. Nesse debate será descrito apenas um desses vetores, o conhecimento psicopatológico. 


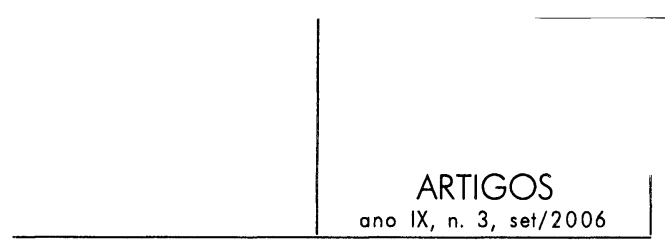

Num primeiro momento serão indicadas as consequiências da adoção da perspectiva da psicopatologia hegemônica na atualidade - a Psicopatologia Descritiva (Berrios, 1993 e 1996) - para o desenho do cuidado realizado nos dispositivos de atenção psicossocial. Em seguida, considerando a premissa de que não há como prosseguir no conhecimento das subjetividades incomuns se não recuperarmos a compreensão de que tais subjetividades continuam, tanto quanto o padrão de subjetividade adotado como modelo de normalidade, a expressar a relação "humano-social", tentaremos mostrar que da adoção dessa posição epistemológica também depende a possibilidade de sustentarmos o desafio da inserção social, questão central desse cuidado. ${ }^{1}$ Para isso partiremos de uma idéia que é pregnante na noção de subjetividade contemporânea - a noção de autonomia - considerada sob a lente de uma tradição psicopatológica específica, a das psicopatologias do ser social.

O conhecimento psicopatológico nos novos dispositivos da assistência psiquiátrica: conseqüências da hegemonia da psicopatologia descritiva para o desenho do cuidado

Homem de aproximadamente quarenta anos, possui longa história psiquiátrica. No período anterior ao início de seu tratamento num Centro de Atenção Psicossocial (CAPS), ${ }^{2}$ onde está há dez meses, esteve internado na Casa de Saúde Dr. Eiras, de Paracambi (RJ), por um ano. Ao sair de alta iniciou frequiência diária no CAPS, inserindo-se numa das oficinas de geração de renda - a cantina. Nessa atividade teve participação ativa, sempre assíduo e interessado. Atendia ao público e auxiliava no controle do estoque e do caixa. Nos dois últimos meses passou a tomar iniciativas pessoais em relação às tarefas que desenvolvia, desconsiderando os acordos coletivos feitos nas reuniões semanais do grupo de trabalho. Permitia, por exemplo, que velhos e conhecidos clientes comprassem

1. A noção de cuidado, freqüente ao longo deste trabalho, tem função constitutiva para o campo da atenção psicossocial. O seu uso pretende ressignificar as noções de tratamento e clínica, em geral definidas a partir de uma concepção de subjetividade universal a-histórica e absoluta, que toma o sujeito apenas a partir de sua dimensão corporal ou psicológica.

2. Os Centros de Atenção Psicossocial (CAPS) são os serviços territoriais estratégicos para a reformulação da assistência psiquiátrica no Brasil, que pretende a substituição progressiva dos hospitais psiquiátricos. Sobre os CAPS, ver Brasil, 2004. 


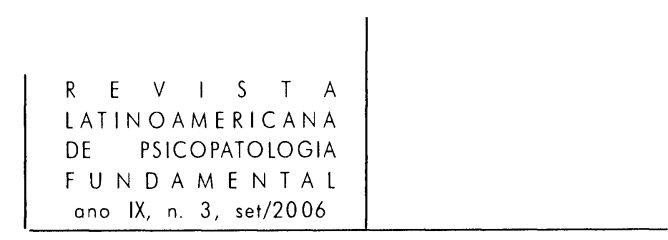

fiado, oferecia pequenos brindes e descontos em compras para os melhores clientes, começou a comprar quantidades maiores para estocar e baratear custos etc. Justificava sua atitude com alguns dos seguintes argumentos: é preciso criar mecanismos que favoreçam a adesão da clientela ao estabelecimento, por isso a necessidade de oferecer-lhes pequenas vantagens que incentivem a fidelidade; ou, ainda, a compra de produtos em maior quantidade deve ser realizada para que os descontos sejam maiores e conseqüentemente diminuam os custos reais das mercadorias. Várias reuniões foram feitas pela equipe que coordenava a atividade, chamando-o à responsabilidade de seus atos. O objetivo dessas conversas era fazê-lo ver que não poderia tomar decisões individualizadas acerca do trabalho que realizava. Solicitavam que respeitasse os espaços coletivos de decisão, privilegiando-os como fórum para a construção de novas regras sobre o trabalho. Nas três últimas semanas, as reuniões para tratar dessa sua mudança abrupta de atitude em relação ao trabalho amiudaram-se. Todavia, nenhuma transformação foi alcançada. Em geral, iniciava tais conversas alegando ser parte da equipe, logo, também com direitos a tomar decisões sobre o trabalho. Embora ao final dessas conversas reconhecesse sempre a necessidade de considerar a instância coletiva, acabava novamente por ignorá-la, tomando decisões por conta própria. Passou a exaltar-se facilmente durante tais reuniões e numa dessas aborreceu-se muito gravemente com a coordenadora. Acusou-a de não compreendê-lo, ser autoritária e querer prejudicá-lo, fazendo-o perder o trabalho. Considerava que essa era a sua atividade mais importante no momento. Ameaçou-a fisicamente e quebrou um forno da cantina. Foi internado em seguida. O diagnóstico na internação foi de transtorno afetivo bipolar com episódio atual maníaco sem sintomas psicóticos. Nessa ocasião foi constatado que havia interrompido o uso da medicação há aproximadamente dois meses.

\section{Situação 2}

Homem de aproximadamente 35 anos, com longa história psiquiátrica, inúmeras internações, e três graves tentativas de suicídio. Numa delas jogou-se na frente de um carro, ocasião em que sofreu várias fraturas. Sua doença teve início no final da adolescência com importante quadro de alucinações auditivas e delírios persecutórios. Nunca apresentou, entretanto, uma trama delirante clara e persistente. Quando sob tratamento, tal sintomatologia desaparecia. Permanecia, todavia, uma atitude agressiva em relação às pessoas, freqüentemente acompanhada de episódios de violência física, especialmente quando se sentia ameaçado, ou, ainda, quando eventualmente se frustrava diante da negativa ao atendimento de algumas de suas demandas. Iniciou tratamento num CAPS há oito meses, encaminhado de uma emergência. Sempre aceitou bem a medicação 


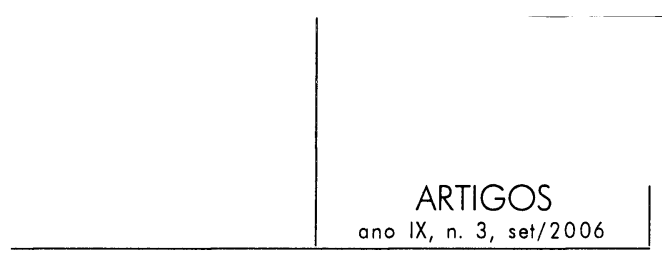

prescrita, com remissão completa da sintomatologia produtiva. Sua atitude diante do tratamento tem sido, apesar disso, absolutamente passiva. Participa das atividades de forma errática e sem empenho visível. Tem, em relação à família, uma queixa que é permanente e centro de suas preocupações: sente-se "roubado" por familiares que ocuparam sua casa, herança dos pais. Sua principal solicitação à equipe é que façam alguma coisa em relação a essa "injustiça". Entretanto, esse não é o seu único pedido: quer roupas, comida, um lugar para ficar, e nunca acha que possa fazer algo por si mesmo. Fala com muito rancor de seus familiares e diz que o melhor a fazer seria matar o seu cunhado, que considera responsável por sua situação de moradia. Não se conforma com o quarto que lhe foi dado pela irmã, nessa mesma casa. Considera isso uma humilhação. No CAPS tem grandes dificuldades em se engajar nas atividades. Aceita o tratamento médico e freqüentemente conversa com a responsável pela oficina de artes, que nomeia como "minha psicóloga". É nesse espaço que passa grande parte do tempo em que está no CAPS. Espera que essa profissional resolva todos os seus problemas, embora não deixe de solicitar insistentemente ajuda aos outros técnicos. A relação com a equipe é sempre tensa: nunca acha que estão interessados em ajudá-lo. Em função disso, recorrentemente comporta-se dos seguintes modos: 1) afirma freqüentemente que quer ser transferido para outro local de tratamento, onde julga, será melhor atendido; ou, 2) ameaça agredir fisicamente um ou outro membro da equipe que acredita, naquele momento, não estar interessado em seus problemas. A grande maioria dos profissionais avalia risco iminente de "passagem ao ato" nas ameaças de violência que apresenta. Num determinado dia chegou ao serviço solicitando a ajuda de sempre, e insistindo na autorização de sua transferência. Porque não foi atendido - a equipe afirmava ser ali o lugar de seu tratamento ameaçou gravemente alguns profissionais com pedras. Exigia, exaltado, a autorização de sua transferência, tendo agredido fisicamente algumas pessoas da equipe e ameaçado de morte outras. Diante de tal situação de tensão e violência, a equipe decidiu por aceitar o seu pedido de transferência. Não via mais possibilidade de tratá-lo. O paciente, então, foi para a emergência de um grande hospital, onde dizia desejar se tratar. Os profissionais dessa emergência contataram o CAPS e, juntos, a seguinte avaliação foi feita: o paciente não estava em crise, logo a emergência não deveria acolhê-lo. Entenderem ainda que a situação não era psiquiátrica. Como consideravam que o comportamento agressivo do paciente não decorria da presença de sintomatologia produtiva, aventaram a possibilidade de chamar a polícia. Todavia, uma vez que as ameaças de morte à equipe eram graves e acionar a polícia levaria tempo, decidiram mantê-lo ali com o propósito de proteger os profissionais ameaçados, até que outra alternativa fosse construída.

A observação das duas situações clínicas relatadas, ocorridas em serviços do tipo CAPS e exemplares do cuidado ali desenvolvido, corroboraram a hipótese 


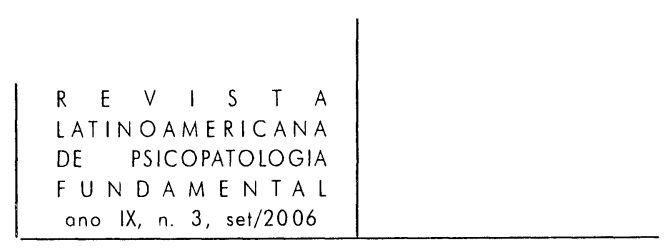

investigada: a psicopatologia adotada nesses serviços é principalmente descritiva. Essas duas situações foram analisadas a partir da busca das noções de doença mental e crise, norteadoras das intervenções realizadas. As concepções encontradas, descritas com detalhes em trabalho anterior (cf. Leal, 2004) e apresentadas brevemente a seguir, indicaram que:

1. A idéia de adoecimento mental adotada não considerou o modo de o sujeito operar no mundo.

2. A idéia de adoecimento mental foi tomada como um evento que acomete o sujeito demandando correção imediata e rápida e nada dizia sobre o seu modo de ser e estar no mundo.

3. A avaliação psicopatológica ficou restrita à indicação da presença ou não de sintomas.

4. Foi privilegiada como indicador do adoecimento mental apenas a observação da presença/ausência de alterações tipo delírios e alucinações.

5. A crise foi entendida apenas como irrupção de sintomatologia produtiva, avaliada sempre como prejudicial, e tomada, na maioria das vezes, com alvo de correção imediata e rápida porque nada dizia do sujeito.

6. A prática assistencial ficou capturada num viés puramente disciplinar, com a realização de avaliações que desconsideraram a subjetividade dos sujeitos em questão.

7. Produziu-se uma dissociação fundamental entre reabilitação e crise, com conseqüente fragmentação do projeto terapêutico.

8. Reabilitar e tratar a crise pautavam-se em intervenções padronizadas normalizantes.

9. O campo da reabilitação foi considerado diverso do campo de cuidado psiquiátrico estrito senso.

As consequiências do uso dessa ferramenta psicopatológica, para o desenho do cuidado clínico, são preocupantes. Uma psicopatologia que se restringe à identificação e descrição de sintomas e se pretende ateórica, não oferece ferramentas para o entendimento da experiência do sujeito que sofre. A tradição psicopatológica hegemônica - a psicopatologia descritiva - desconectou-se integralmente de sua base epistemológica. Perdeu as características que, segundo Stanghellini (2004), deveriam defini-la: “... iluminar primariamente a qualidade das experiências subjetivas, seus significados pessoais e o padrão pelo qual elas estão situadas como partes de totalidades significativas (...) principalmente concernidas à corporificação e a intersubjetividade" (p. 9). Entretanto, a investigação psicopatológica, na atualidade, concentrou-se nos sintomas psicóticos que têm lugar no indivíduo enquanto ser isolado; afastou-se das estruturas vulneráveis de sua consciência, estudadas no contexto do seu mundo-vida. Reflexões sobre o manejo das 


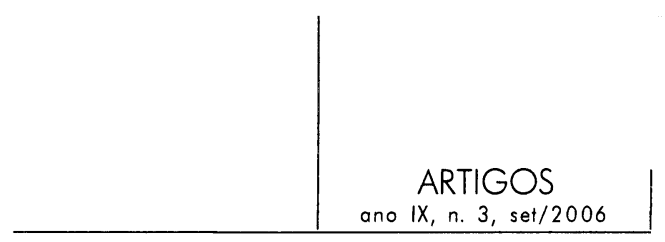

dificuldades com o laço social, para cada uma das formas específica de adoecimento mental, ficaram igualmente limitadas porque o interesse pelas alterações psíquicas decorriam de uma compreensão do sujeito apreendido em separado de sua relação com o mundo. A tematização da relação do sintoma com o sujeito também ficou inviável. Faltaram instrumentos que permitissem esse exercício.

Esse conjunto de limitações acima descrito deriva das características que são próprias a essa perspectiva psicopatológica. Alguns de seus críticos, como Stanghellini \& Ballerini (2002), a definem como solipsista, isto é, incapaz de tematizar a experiência do sujeito no mundo e com o mundo. Ao constituir toda a sua análise sobre o sujeito isolado do mundo, a ferramenta psicopatológica construída nesses moldes tornou-se incapaz de enfrentar o desafio central do cuidado nos novos dispositivos: contribuir para o desenho de um cuidado que considere a experiência do sujeito no mundo e com o mundo.

Que vicissitudes estariam abertas para a clínica desses novos dispositivos, se fosse adotada uma perspectiva psicopatológica que tomasse a relação ser-nomundo como o seu ponto zero, abandonando a crença ingênua numa realidade ontológica não relativa aos seus contextos de determinação?

As psicopatologias do ser-no-mundo: ferramentas para a construção do cuidado que visa promover a autonomia possível?

A partir do final dos anos 1960, alguns autores, na maioria psiquiatras, principalmente de países da Europa (Alemanha, Dinamarca, Itália e Holanda), do Japão e de parte da América do Norte, iniciaram um debate sobre a psicopatologia que ganhou força especialmente nas últimas décadas (cf. Rulf, 2003). ${ }^{3}$ Baseados em filósofos como Husserl, Heidegger e Merleau-Ponty, aqueles autores alegavam que o esforço principal da psicopatologia deveria ser iluminar a qualidade da experiência subjetiva, seus sentidos pessoais e a relação que esses sentidos particulares estabelecem com o todo. Para dar consequiência a esses estudos, tais autores retomaram uma tradição psiquiátrica já presente no início do século, representada dentre outros por Minkowski (1927, 1933), Binswanger (1945) e Wyrsch (1952). A finalidade principal da descrição das características essenciais dos aspectos da consciência humana e do ser-no-mundo era, para esses autores contemporâneos, conhecer como o sujeito constitui o seu mundo. Para tal

3. Ver também Blankenburg (1971), Bovet \& Parnas (1993), Monti \& Stanghellini (1996), Naudin et al. (1999), Parnas (2003), Parnas \& Bovet (1991, 1995), Parnas, Bovet \& Zahavi (2002), Sass (2003), Sass \& Parnas (2003); Stanghellini (2000, 2004), Stanghellini \& Ballerini (2002). 


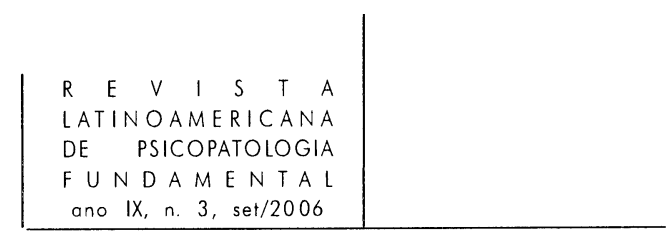

romperam com as tradições psicopatológicas mais comuns, abandonaram a compreensão fenomenológica que fazia do mundo mero produto da mente individual e privilegiaram a tradição fenomenológica que tomava a dimensão social como algo diverso do mundo que jaz na mente de cada um.

Nessa perspectiva, as experiências anormais do eu são sempre consideradas expressões da relação humano-social. Essa mudança, absolutamente fundamental e inovadora para a clínica, toma os modos de relação humano-social não mais como efeito de alterações oriundas do sujeito. Solo primeiro das alterações psicopatológicas, a relação humano-social é considerada constitutiva do próprio ser. Para esses autores o humano é desde sua origem social, marcado por duas dimensões:

a) o sujeito reflexivo, da narrativa, produto da relação intersubjetiva mediada pela linguagem;

b) mas também o ser que o embasa, um ser corporal, experiencial, pré-reflexivo, que mesmo assim ainda é fruto de uma relação intersubjetiva, embora antepredicativa (cf. Zahavi, 2003).

O mundo social, nessa tradição psicopatológica, não é estabelecido meramente por uma ordem prescritiva - conjunto de regras aceito por todos -, mas também por uma ordem interpretativa. Esta última é válida para todo sujeito pertencente a um dado contexto cultural, no qual cada participante a recebe espontânea e "naturalmente", de modo intuitivo, ante-predicativo, pré-reflexivo.

Esses autores, que tomam o ser como social desde a sua origem e que mantêm a mente individual articulada ao fenômeno social, sustentaram que as alterações da consciência acontecem nessas duas dimensões da relação do sujeito com o mundo: uma predicativa e uma ante-predicativa.

Ao definirem sujeito e mundo como conceitos complexos marcados por mais de uma dimensão, o propósito era:

a) afirmar que não é possível separar a mente individual do fenômeno social, quando o objetivo é analisar o processo através do qual atribuímos sentido aos objetos e aos eventos do mundo;

b) indicar que o mundo social não é puro produto da mente individual, isto é, que o entendimento do outro não decorre apenas de inferência do estado mental, mas da relação intercorporal;

c) indicar que o mundo social não se constitui exclusivamente de uma dimensão narrativa - dimensão cognitiva e reflexiva -, mas é também uma experiência precognitiva intuitiva, uma "percepção direta" da vida emocional do outro.

d) indicar que a perturbação da percepção intuitiva da realidade intercorporal promovem desordens tanto da percepção de si quanto dos limites existentes entre o eu e os outros. 


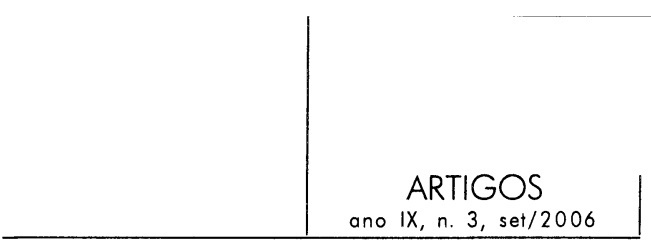

Mas se a subjetividade é desde sempre expressão da relação "humanosocial", e não pode ser compreendida como do âmbito exclusivo da singularidade, como enfrentar a questão da autonomia - gravemente comprometida nos pacientes com transtornos mentais graves, persistentes e nos pacientes em crise - que nos novos dispositivos tornou-se algo a ser promovido pelo e com o tratamento?

A subjetividade envolve idéia de autonomia, liberdade, auto-reflexividade, auto-responsabilidade, materialidade de um corpo, particularidades, potencialidades infinitas que conferem cunho próprio e único à personalidade (cf. Souza Santos, 1995, p. 120). Na modernidade a idéia de autonomia é, sem dúvida, uma representação imediata da liberdade humana. É um valor que qualifica e caracteriza o humano e afirma o indivíduo como um princípio (cf. Renault, 1999). E isso não é diferente para o campo do cuidado nos novos dispositivos. Podemos dizer, de forma caricatural, que muitos de nós, nesse campo, chegamos mesmo a tomar a "produção da autonomia" como um certo ideal de "cura". A autonomia freqüentemente é considerada o que de mais importante o processo de tratamento tem a produzir. Mas será que essa noção informa as nossas ações, exatamente como a estamos compreendendo? Que implicações poderiam, eventualmente, advir de tomá-la, nas suas mais variadas acepções, como referência para a prática de cuidado?

A palavra autônomo vem do grego autos - que quer dizer si mesmo - e nomos - que quer dizer lei, regra, norma - ou seja, significa aquele que tem o poder de dar a si mesmo a norma, a regra, a lei. Aquele que goza de autonomia e liberdade seria aquele com capacidade plena de autodeterminação.

Todavia, se levantamos o véu do individualismo, próprio do nosso tempo, percebemos que essa independência absoluta do sujeito em relação à sociedade é mais um mito de nossa cultura. Se todo ser é desde a sua origem social, o prérequisito de nossa liberdade não pode então ser concebido, como supomos correntemente, como independência absoluta do mundo que nos cerca, representado pela máxima: o mundo somos nós mesmos. O pré-requisito da liberdade, como dirá Stanghellini (2004), é a capacidade de pôr entre parênteses a representação preestabelecida do mundo, ou o conhecimento do senso comum, sem, entretanto, perder nossa histórica articulação com o mundo comum.

E é exatamente isso que está alterado em nossos pacientes com transtornos mentais graves, persistentes, e pacientes em crise: a capacidade de pôr entre parênteses o conhecimento do senso comum e ao mesmo tempo manter com o mundo comum essa articulação histórica que é desde sempre e a todo tempo constitutiva de nós mesmos. Em geral, esses pacientes, quando conseguem pôr o mundo entre parênteses para preservar a sua liberdade, o fazem também 


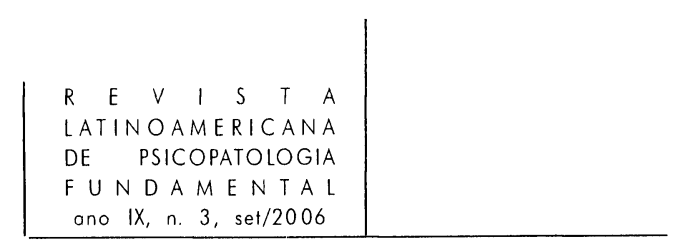

perdendo junto a capacidade de preservar, de algum modo, essa articulação processual que é constitutiva de nós mesmos. Ou vice-versa, se são capazes de manter essa articulação com o mundo são incapazes de pôr entre parênteses a representação preestabelecida do mundo.

Para fins do nosso argumento é importante perceber aqui que, enquanto agenciadores do cuidado, não podemos ignorar que a capacidade de pôr entre parênteses é tão necessária quanto a capacidade de assimilação - aquela que nos dá a experiência de pertencimento ao mundo - e que ambas estão dialeticamente inter-relacionadas. Estratégias de intervenção que promovam a autonomia desses sujeitos concebendo-a como independência absoluta do mundo serão iatrogênicas, porque estarão investindo em ampliar as dificuldades que são centrais para essas pessoas: a sua relação com o mundo. A ignorância acerca dos padrões diferenciados de relação desses sujeitos com o mundo os empurrará ainda mais para o campo do sofrimento.

Os novos serviços de assistência psiquiátrica deverão rever como estão tentando operar, no desenho do cuidado, o paradigma que os organiza, ou seja, o paradigma da inserção social. Não será mais possível manter a ilusão de que a forma de enfrentamento da dificuldade de constituição de laço social, ou da disfunção social, como também é chamada, próprias a esses pacientes, é indiferente para os efeitos da intervenção.

O enfrentamento da disfunção social não poderá mais, como se vê nas diversas tradições psiquiátricas (Stanghellini, 2004 e Stanghellini \& Ballerini 2002), ser:

a) concebida como fenômeno que é conseqüência do processo de doença e não um dos seus elementos;

b) tratadas de forma indistinta, sem que a particularidade desse fenômeno em cada caso psicopatológico seja considerada;

c) manejadas com recursos meramente adaptativos que não considerem a experiência subjetiva dos pacientes.

As formas de apresentação das dificuldades do estabelecimento de laço podem ser semelhantes, mas com certeza o modo de experimentá-las não é.

A observação do fenômeno da disfunção social pela lente da psicopatologia do ser social desautoriza, por causa do modo como a sua produção é compreendida, qualquer separação entre ações de tratamento e reabilitação. Nesse contexto perdem relevância tanto as estratégias de treinamento de habilidades sociais quanto aquelas que buscam o ajustamento social pelo treinamento da capacidade de internalizar regras e comportamentos sociais. Ganha importância o desafio de construção de atividades e ações de reabilitação que possam dialogar com a experiência vivida desses sujeitos e com os modos 


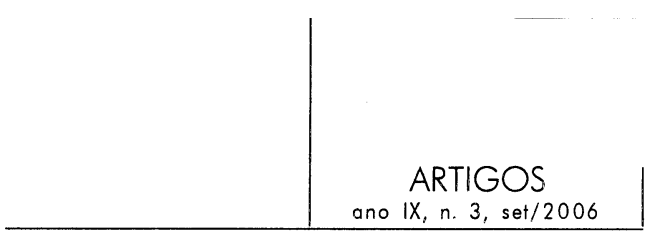

de produção das dificuldades de relação com o mundo presentes em cada quadro psicopatológico.

Uma última observação sobre a compreensão da disfunção social como consequiência do adoecimento mental e não como sintoma, e da consequiência dessa compreensão para a idéia de autonomia. A psicopatologia descritiva, tendência mais comum nos serviços do tipo CAPS, favoreceu que fenômenos tais como alucinação e delírio fossem indicadores privilegiados do adoecimento mental. Em tempos de eficácia cada vez maior dos tratamentos psicofarmacológicos, a forma de apresentação de sintomatologia positiva, entretanto, tem sofrido grandes transformações. É cada vez mais comum encontrarmos síndromes esquizofrênicas em que as dificuldades de relação com o mundo são mais frequientes e intensas do que a presença de sintomas positivos. Os quadros psiquiátricos paulatinamente assemelham-se às velhas tragédias descritas por autores como Minkowski - com o autismo pobre - Kahlbaum - com a idiotia moral - e Hecker - com a hebefrenia. Expresso em geral por anormalidades pseudo-sociopáticas, esses quadros gradualmente se aproximam do que hoje se classifica de desordens de personalidade. ${ }^{4}$ Os CAPS, em função dessas mudanças, correm um grande risco. Pela sua opacidade, as lentes da psicopatologia descritiva não nos oferecem a acuidade necessária para a observação desse ponto, colocando-nos na iminência de deixar de fora do campo do cuidado psiquiátrico as pessoas que se apresentam desse modo. Ao considerar que a autonomia de um sujeito só estaria comprometida diante da presença de sintomas positivos, porque a entendemos apenas como capacidade de autodeterminação e não como fruto da capacidade de pôr o mundo entre parênteses e ao mesmo tempo preservar o nosso sentimento de pertencimento a ele, havemos de cuidar para que, como psiquiatras, não protagonizemos um novo processo de marginalização da doença mental. Empurrar aqueles que antes eram reclusos nos hospitais psiquiátricos para fora da prática psiquiátrica pode ser igualmente iatrogênico.

A relação do clínico com o fenômeno não pode, portanto, ser considerada uma relação neutra, isenta, ele é concernido pelos fenômenos que observa. ${ }^{5} \mathrm{~A}$

4. A personalidade foi uma categoria que teve o seu sentido significativamente transformado no último século. De substrato da doença, indicador da dimensão do humano, passou a ser considerado um indicador exclusivo do comportamento, da mesma forma que outros sintomas. Sobre essa discussão, ver Leal, 2004.

5. Stanghellini (2004) indicou que embora a psicopatologia de Jaspers fizesse justiça à experiência do paciente, colocava os fenômenos esquizofrênicos do lado da incompreensibilidade. Essa noção seria decorrente, segundo o autor, de uma resistência por parte do próprio Jaspers em abordar os fenômenos que escapavam ao sentido esperado. Com isso, Stanghellini quer mostrar que a falta de empatia não seria uma dificuldade clínica, mas, antes, uma dificuldade do próprio clínico. 


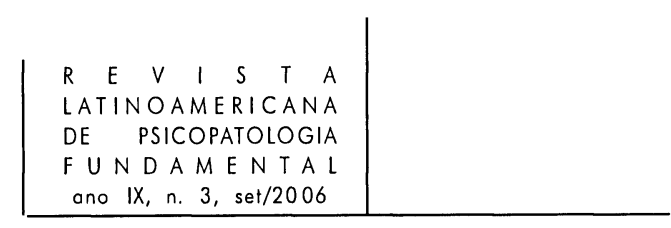

identificação de um fenômeno como marca do adoecimento mental deve implicar o clínico na busca de soluções que não podem ser desarticuladas do social. A psicopatologia do ser social, ao recuperar para a psiquiatria modos de ver perdidos no passado, felizmente pode oferecer instrumentos de leitura mais sensíveis que não mantenham, em novos moldes, a estigmatização da doença mental através dos tempos.

\section{Referências}

Berrios, German E. Phenomenology and psychopathology: was there ever a relationship? Comprehensive Psychiatry, v. 34, n. 4, p. 213-20, 1993.

The History of Mental Symptons. Descriptive psychopathology since the nineteenth century. Cambridge: Cambridge University Press, 1996.

BinswANGER, Ludwig (1945). Sur la direction de recherche analytico-existentielle en psychiatrie. In: Analyse existentielle et psychanalyse freudienne. Discours, Parcours, et Freud. Paris: Gallimard, 1970. p. 51-84.

BLANKENBURG, Wolfgang (1971). La perte de l'évidence naturelle. Une contribution à la psychopathologie des schizophrénies pauci-symptomatiques. Paris: PUF, 1991.

Bovet, Pierre \& PARNAS, Josef. Schizophrenic delusions: a phenomenological approach. Schizophrenia Bulletin, v. 19, n. 3, p. 579-97, 1993.

BraSIL, M. S. Saúde mental no SUS: os centros de atenção psicossocial. Brasília: MS, 2004. Disponível em www.saude.gov.br/saudemental.

LEAL, Erotildes Maria. Psicopatologia do senso comum: uma psicopatologia do ser social. In: Silva F., J. F. (org.) Psicopatologia hoje. Rio de Janeiro: UFRJ, no prelo.

$O$ conhecimento psicopatológico enquanto instrumento clínico da atenção psicossocial: notas. Trabalho apresentado no XXII Congresso Brasileiro de Psiquiatria. Salvador: Bahia, 2004 (em preparação para publicação).

Minkowski, Eugene (1927). La schizophrénie. Paris: Éditions Payot \& Rivages, 1997.

(1933). Le temps vécu. Paris: PUF, 1995.

Monti, Mario Rossi \& Stanghellini, Giovanni. Psychopathology: an edgeless razor? Comprehensive Psychiatry, v. 37, n. 3, p. 196-204, 1996.

Naudin, Jean; Gros-Azorin, Caroline; Mishara, Aaron; Wiggins, Osborne P.; SchwartZ, Michael A. \& Azorin, Jean-Michel. The use of the Husserlian reduction as a method of investigation in psychiatry. In: VARelA, F. J. \& SHEAR, J. (ed.). The View from Within. First-person Approaches to the Study of Consciousness. Thorverton: Imprint 


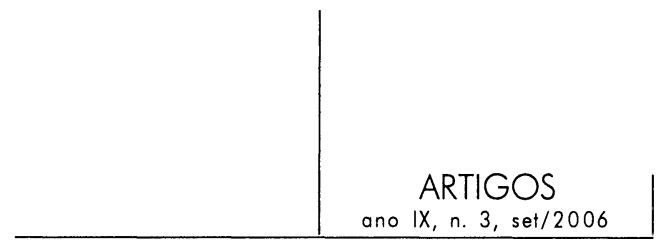

Academic, 1999. p. 155-71.

PARnAS, Josef. Self and schizophrenia: a phenomenological perspective. In: KIRCHER, T. \& David, A. S. (ed.). The Self in Neuroscience and Psychiatry. Cambridge: Cambridge University Press, 2003. p. 217-41.

Parnas, Josef \& Bovet, Pierre. Autism in schizophrenia revisited. Comprehensive Psychiatry, v. 32, n. 1, p. 7-21, 1991.

; ___ Research in psychopathology: epistemological issues. Comprehensive Psychiatry, v. 36, n. 3, p. 167-81, 1995.

Parnas, Josef; Bovet, Pierre \& Zahavi, Dan. Schizophrenic autism: clinical phenomenology and pathogenetic implications. World Psychiatry, v. 1, n. 3, p. 131-6, 2002.

Renault, Alain. Avant-propos: Liberté, Egalité, Subjectivité. In: Renault, A. (org.) Histoire de la philosophie politique. Tome II: Naissances de la Modernité. Paris: Éditions Calmann- Lévy, 1999.

Rulf, Sybille. Phenomenological contributions on schizophrenia: a critical review and commentary on the literature between 1980-2000. Journal of Phenomenological Psychology, v. 34, n. 1, p. 1-46, 2003.

SASS, Louis A. Self-disturbance in schizophrenia: hyperreflexivity and diminished selfaffection. In: KIRChER, T. \& DAVID, A.S. (ed.). The Self in Neuroscience and Psychiatry. Cambridge: Cambridge University Press, 2003. p. 242-71.

Sass, Louis A. \& Parnas, Josef. Schizophrenia, consciousness and the self. Schizophrenia Bulletin, v. 29, n. 3, p. 427-44, 2003.

Souza Santos, Boaventura. Pela mão de Alice. O social e o político na pós-modernidade. 4. ed. Porto: Edições Afrontamento, 1995.

Stanghellini, Giovanni. At issue: vulnerability to schizophrenia and lack of common sense. Schizophrenia Bulletin, v. 26, n. 4, p. 775-87, 2000.

Disembodied Spirits and Deanimated Bodies. The Psychopathology of Common Sense. Oxford: Oxford University Press, 2004.

StANGHEllini, Giovanni. \& BALlerini, M. Dis-sociality: the phenomenological approach to social dysfunction in Schizophrenia. Word Psychiatry; v. 1, n. 2, p. 102 -6, 2002.

WYRSCH, Jakob. La persona del esquizofrenico. Estudios sobre la clinica, psicología y modalidad existencial. Madrid: Morata, 1952.

Zahavi, Dan. Phenomenology of self. In: Kircher, T. \& David, A. S. (ed.). The Self in Neuroscience and Psychiatry. Cambridge: Cambridge University Press, 2003. p. 56-75. 


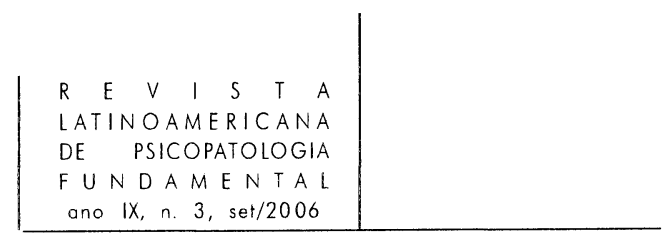

\section{Resumos}

El lugar que el conocimiento psicopatológico ha ocupado y puede llegar a ocupar en la práctica clínica de los centros para atención psico-social (CAPS) - espacios comunitarios destinados al tratamiento de pacientes con trastornos mentales graves, persistentes, en cuadros agudos o no - es el tema central de este trabajo. Se analizan brevemente las consecuencias de la hegemonía de la psicopatología descriptiva para el trazado de las intervenciones en esos servicios y se discute si la psicopatología del ser social pudiera ser una herramienta para la construcción de cuidados que promuevan la autonomía posible para que los pacientes puedan vivir en comunidad.

Palabras claves: Autonomía, psicopatología del ser social, psicopatología del sentido común, atención psico-social

La place que la connaissance psychopathologique occupe, et peut venir a occuper, dans la pratique clínique des centres de soins psycho-sociaux (CAPS) - centres communautaires destinés au traitement de patients porteurs de problèmes mentaux graves, persistants, en cadres aiguës ou non - est lê thème central de cet article. On analyse brièvement les conséquences de l'hégémonie de la psychopathologie descriptive pour le dessein des interventions dans ces centres et on discute si la psychopathologie de l'être social pourrai être un instrument pour la construction d'un soin capable de promouvoir une autonomie possible pour que les patients puissent vivre en communauté.

Mots clés: Autonomie, psychopathologie de l'être social, psychopathologie du sens commun, soins psycho-sociaux

The main question of this article is: what is the place of psychopathological knowledge in governamental centers for psychosocial attention (CAPS) in Brazil, and what it might be. Such centers are located in neighborhoods to treat patients with severe mental disorders. In the article, consequences of the hegemony of descriptive psychopathology in clinical interventions at these services are analyzed, as well as the question of whether the psychopathology of the social being might be a tool in the treatment of such patients in their communities.

Key words: Autonomy, psychopathology of the social being, common sense psychopathology, psychosocial care

Versão inicial recebida em novembro de 2005

Versão revisada recebida em março de 2006 